\title{
Power, Play and Pedagogy through the PowerPoint Performance-Lecture
}

\author{
Kai Syng Tan
}

\author{
Manchester School of Art, Manchester Metropolitan University, UK
}

\begin{abstract}
What could a visual-led approach to the learning and teaching of complex issues look like for a short online synchronous session? Through a playful performance-lecture exploring concepts in diversity, interdisciplinarity and social change entitled "What could a neurodiversity-led 2050 look like?", this paper outlines the possibilities of visual-centred approach, using the ubiquitous Microsoft software PowerPoint (or opensourced equivalents like Google Slides and Prezi). It seeks to contribute to discourses and practices around role of visual approaches in Higher Education (HE) to address 'difficult' topics like power and inequality in an engaging manner, and to empower learners as active participants, including those who may be think visually, such as dyslexic learners. Such approaches will be urgent in a reality characterised by profound socio-political injustice highlighted by Black Lives Matter (BLM), and amid a global pandemic, where teaching occurs online, and where learners and teachers alike may be short of time, attention and resources. Highlighting techniques and perspectives from art, film and neurodiversity, it invites the consideration of the PowerPoint performance-lecture as a simple yet engaging and responsive process for higher order learning and creative thinking. A secondary point of the article to call for HE to itself apply a degree of critical and creative thinking about its own position, to use self-knowledge to do better, in order to move forward. It welcomes feedback and challenges, and calls for the creation of yet more playful, innovative, visual-led approaches in the learning and teaching of complex issues in Higher Education.
\end{abstract}

Keywords: Performance-Lecture; Diversity; Higher Education

Received: 6 August 2020

ISSN 2056-757X

Revised: 16 August 2020

Accepted: 4 September 2020

https://doi.org/10.18646/2056.73.20-028 


\section{Introduction}

What could a visual-led approach to the learning and teaching of complex issues look like for an online synchronous session? Through a playful performance-lecture exploring concepts in diversity, interdisciplinarity and social change that I presented recently, What could a neurodiversity-led 2050 look like? (hereafter 2050), this paper outlines the possibilities of visual-centred approach, using the ubiquitous Microsoft software PowerPoint (or open-sourced equivalents like Google Slides and Prezi). I will distribute the slides throughout the article to punctuate this discussion (Figure 1).

Figure 1: Slide 1 of What could a neurodiversity-led 2050 look like? (Tan 2020d)

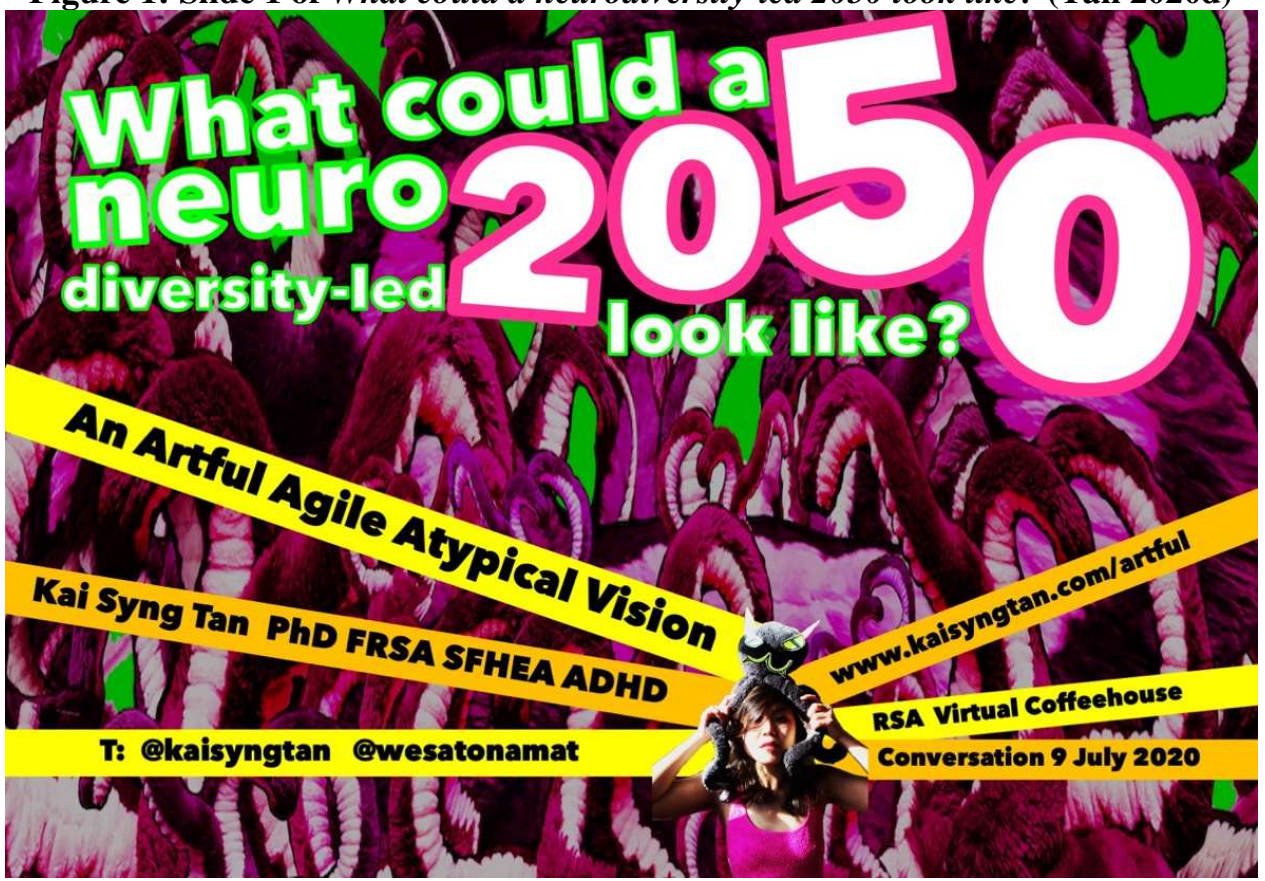

The component images have been performed, photographed, then manipulated by the author.

I seek to contribute to discourses and practices around role of visual approaches in Higher Education (HE) to address 'difficult' topics like power and inequality in an engaging manner, and to empower learners as active participants, including those who may be think visually, such as dyslexic learners. Such approaches will be urgent in a reality characterised by profound socio-political injustice highlighted by Black Lives Matter (BLM), and amid a global pandemic, where teaching occurs online, and where learners and teachers alike may be short of time, attention and resources. Highlighting techniques and perspectives from art, film and neurodiversity, I invite the consideration of the PowerPoint performance-lecture as a simple yet engaging and responsive process for higher order learning (Marton and Säljö, 1976) and creative thinking, requiring the application of 'multiple theories and concepts', 'a variety of skills, techniques and methods' and 'using self-knowledge and personal cognition' (Hanna, 2007: 9-10). A secondary point of the article to call for HE to itself apply a degree of critical and creative thinking about its own position, to use self-knowledge to do better, in order to move forward.

International Journal of Management and Applied Research, 2020, Vol. 7, No. 3 
I welcome feedback and challenges, and call for the creation of yet more playful, innovative, visual-led approaches in the learning and teaching of complex issues in HE.

\section{The visual in HE: an inferior and illegitimate cousin to words?}

Globalisation and digitisation have led to the 'visual turn' in the last twenty years, which has profoundly transformed communication (Roberts, 2017). This affirms the power and poetry of the imagery that can enhance or surpass spoken or written words (Figure 2). Emojis- cutesy ideograms that originated on Japanese mobile phone in the 1990's - now speak the thousands of words that we struggle to use to convey our emotions (Stark and Crawford, 2015). Revolutions are being plotted across images and short texts: for example, the use of Twitter during the Arab Spring (Bruns, Highfield, and Burgess, 2013) and WhatsApp during the 'Umbrella Revolution' (Lee, So, and Leung, 2015). The photograph of Alan Kurdi washed ashore became an iconic symbol for the migrant crisis, causing a global surge of sympathy and rise in charity donation (Ibrahim, 2018).

Figure 2: Slide 9 from 2050 (Tan 2020d)

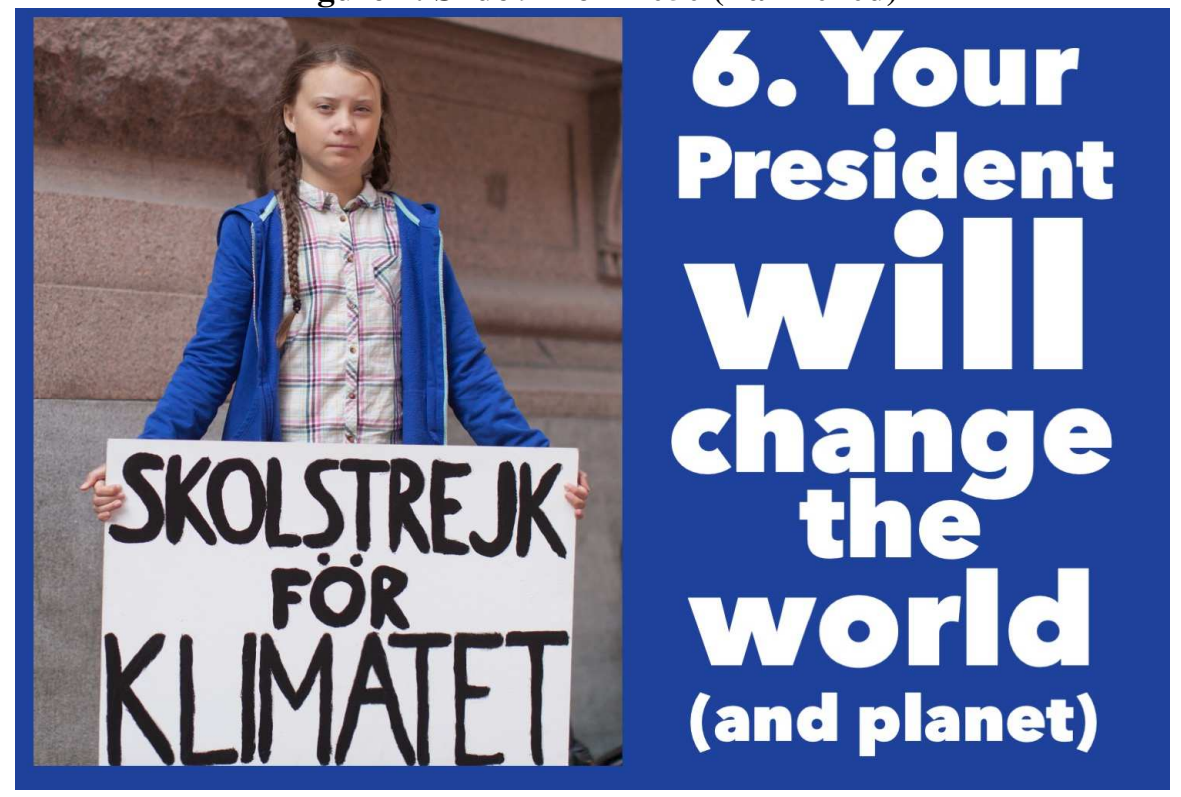

The photograph is of the autistic climate activist Greta Thunberg (Hellberg 2018).

Yet, already notoriously reluctant to respond to social change (Bhopal and Pitkin, 2020) but swift to defend its identity or status when it feels threatened (Sian, 2019), HE could be said to remain largely indifferent to multimedia learning (MML). According to Mayer (2014, preface), "multimedia learning, or learning from words and images, has developed into a coherent discipline with a significant research base". Graphs, photographs, video clips and more most certainly grace our textbooks, Moodle, Blackboards and Zoom. Platforms like Powerpoint have been around for decades, a quick Google Scholar search on 'multimedia learning' returns 3,450,000 results, and the longevity of a journal like Visual Communication, which has been around since 2002, confirms that the visual is firmly in HE.

International Journal of Management and Applied Research, 2020, Vol. 7, No. 3 
Nonetheless, questions about the status of the visual within learning and teaching remain. In a largely logocentric culture within HE, aren't words - written and spoken the lingua franca, not visual language? Could MML be considered a 'bolt-on', inferior to text, or regarded as resource-intensive (requiring more time, copyright clearance and more) or, at worst, not taken as a legitimate, formal pedagogical approach (Roberts, 2018)? If visual language pull its own weight in the HE sphere, why must every image used be translated and explained into words, via caption or as reference within bodies of text, for them to have any legs, and are other dismissed as standalones? This is despite how, activated in representative, metaphorical or 'paradoxical' ways, images have been proven to have the capacity to support discussion, and convey meaning and engagement around the learning and teaching of complex subjects, including politics in the global south, peace and conflict studies and international history (Roberts, 2017). Visual tools can be a short cut to play and metaphor, which is known to nurture higher order learning and creative thinking by encouraging reflecting, opening up and sharing (Nerantzi, 2018), and provides the learner with insights into complex situations, the understanding of self and others (Marton and Säljö, 1976). Studies have shown that, although visual tools do not improve student performances significantly, students prefer image-based slides, and understand better with the use of visual tools (Bartsch and Cobern, 2003). Yet, HE continues to miss the trick.

\section{Tricky Topics}

If $\mathrm{HE}$ is insecure about a non-threat like MML, it is not difficult to gauge its level of angst in the face of the ongoing, terrible twin of wicked problems: the Covid-19 pandemic and Black Live Matters movement (BLM), and the larger issue of inequality and injustice.

UK HE is racist. This is well-established (e.g. Adomako Ampofo, 2016; Bhopal and Pitkin, 2020, Sian, 2019). Priding themselves as 'liberal' and 'post-racial' universities perpetuate "patterns of privilege" that are "structured by whiteness", inflicting micro and macro-aggressions to staff and students of colour (Sian, 2019). It took the scale and gravity of the 2020 BLM - sparked by 8 minutes and 46 seconds of moving images of George Floyd's killing - to force some universities to act. A few have admitted that they "haven't always got it right" (Bhopal and Henderson, 2019: 37), while others have devised imaginative PR moves (Bhopal and Pitkin, 2020).

But if UK HE didn't want to address racism pre-Covid-19, the global economic recession and socio-political volatility - Brexit, anyone? - provide great cover for many to resist, ignore or deny the call for diversity. Which is why academics and students of colour as well as allies continue to apply pressure, particularly through social media platforms, given social-distancing rules in UK. Twitter, for instance, has been an effective public stage for people to call out on institutions' past and historical wrongdoings (Adomako Ampofo, 2016; BBC News, 2020; Haynes and Bazner, 2019), or to bring visibility - literally - to 'black excellence in neuro-fields' with crowdsourced selfies by black neuroscientists in \#BlackinNeuro. Each selfie or emoji in each tweet - or, for that matter, WhatsApp message or Instagram post - presents a readymade teaching goldmine to trigger discourse, invite contemplation and debate in the online classroom.

International Journal of Management and Applied Research, 2020, Vol. 7, No. 3 
But what I wish to discuss is a simpler, 'old school' and even bland MML tool - the PowerPoint, which has entered offices and classrooms since 1987 (Encyclopaedia Britannica 2020) - for an online audience, through an example of a recent commission.

\section{Playing with Power Structure using the PowerPoint}

On 9 July, I presented 2050 on Zoom. This was part of Virtual Coffeehouse Conversation: Neurodiversity and the Future of Work (Tan, 2020d). The invitation was a result of a well-received op-ed I wrote, on artistic and neurodivergent leadership in the Covid-19 recovery (2020b), and was organised by the Royal Society of Arts (RSA). Set up in 1847, the RSA is an organisation committed to finding practical solutions to social challenges. I have been a Fellow since 2014, and past Fellows include Charles Dickens, Benjamin Franklin, Karl Marx and Tim Berners-Lee. The session was attended by up to 130 people at a point. RSA Fellows aside, they include academics in Higher Education and theatre, curators, PhD students in neuroscience, activists in neurodiversity, media artists, neurodivergent technologists. The 60-minute event featured another speaker, and each of our 10-minute presentation was followed by discussions in breakout rooms, and a final open forum.

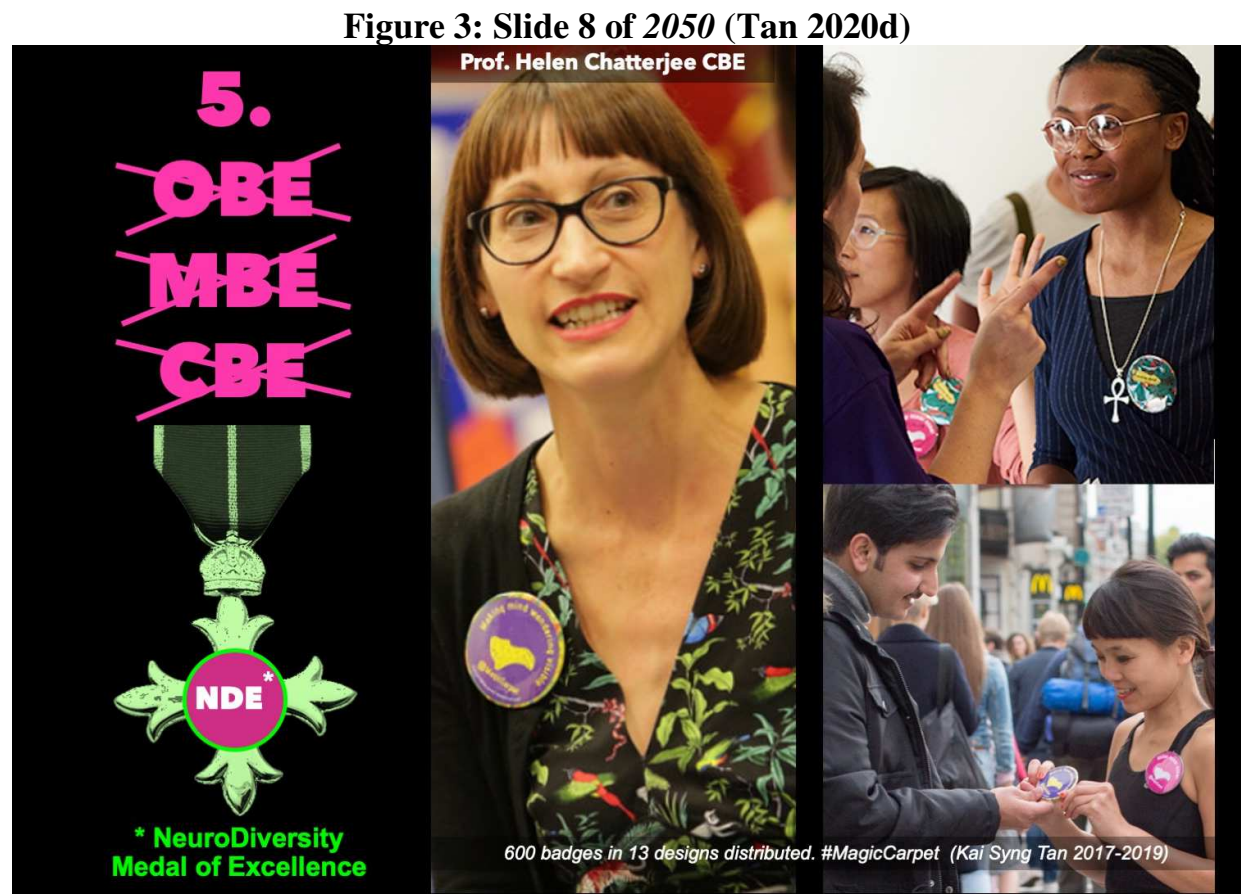

The source image of the medal is a photograph of the OBE medal (Empire Medals 2020) The other photographs are by team members of the project \#MagicCarpet (Tan 2017).

Across 12 slides, I shared eight visions of the future. This was my creative, neurodivergent and decolonised interpretation and interrogation of RSA's own outline of the future. Situated in the year 2050, my version celebrates - not ignore or punish people with 'non-standard' cognitive, communication and learning modes, including those with dyslexia, Attention Deficit Hyperactivity Disorder (ADHD), autism and more, and how these intersects with race, class and gender. 2050 is snappy - fast-paced, as well as irritated and impatient with the socio-political injustices and hungry for

International Journal of Management and Applied Research, 2020, Vol. 7, No. 3 
change. Satirical and absurd, it is also angry and hopeful. Instead of OBE/MBE/CBE ('Haven't we had enough of the empire?', I asked), I urged for NDE - NeuroDiversity medals of Excellence (Figure 3). By the next generation, HE should also finally stop failing or boring people with divergent learning approaches. Instead, it will reward interdisciplinarity and intellectual promiscuity with MASc and PhDs. Rather than penalising those who can't read or write, or who cannot sit still, we will celebrate the next generations of Leonardo Da Vinci-s, whose dyslexia and ADHD are behind his prolificacy and polymathy (eg Catani and Mazzarello 2019; Røsstad 2002; Mangione and Maestro 2019). I also suggested that, in 30 years' time, 'neurodiversity' will also be truly diversified, and we will stop using the excuse of the fight against ableism and neuro-normativity to perpetuate white privilege, racism and elitism, but celebrate people in all shades and interpretations, identifications and presentations of neurodiversities.

Reactions were highly-positive (Figure 4). Feedback in the form of 12 tweets, 6 emails and live chat reveal that concepts learnt invited further reflection and evaluation of issues around workplace discrimination, racism, and systemic change. There were also 4 new subscriptions to a network I co-lead on neurodiversity, an invitation to repeat the presentation, and another to be Co-Principal Investigator for an interdisciplinary funding bid on neurodiversity in adolescents to the Medical Research Council.

Figure 4: Screenshots of tweets, emails and live chat, in response to the RSA presentation, and the repeated performance at University of Reading (2020)

What an awesome talk from @kaisyngtan as part of the virtual coffee house @theRSAorg - we need to be ill-disciplines and tentacular in 2050

\#neurodiversity \#future \#play \#risk \#brave \#silverlining

Kai @kaisyngtan a call to be playful, to be curious about everything! Break free from boredom! \#creativeHE

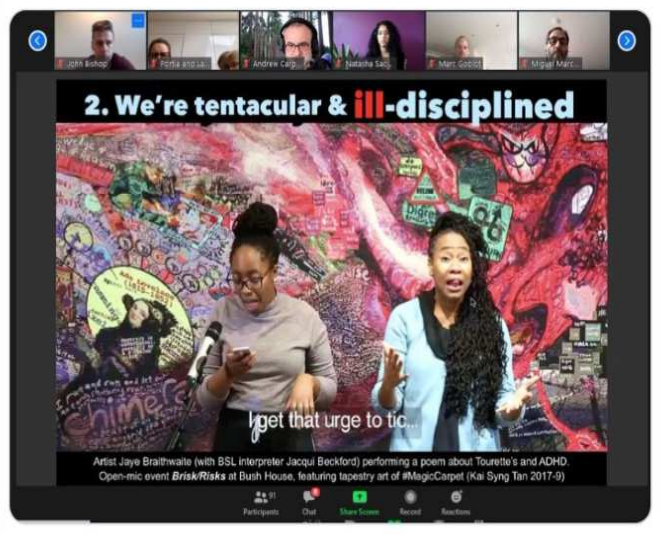

Hi Kai, Great lecture!!! it was great listening to you! I was sitting through it and nodding over and over! it was like listening to music!

A couple of things. I have a background in Art education (PGCE FAHE but never been able to get to teach in Higher Ed) and wanted to extend this conversation about how art is taught. Do you have time to talk? Also can we work on this together???

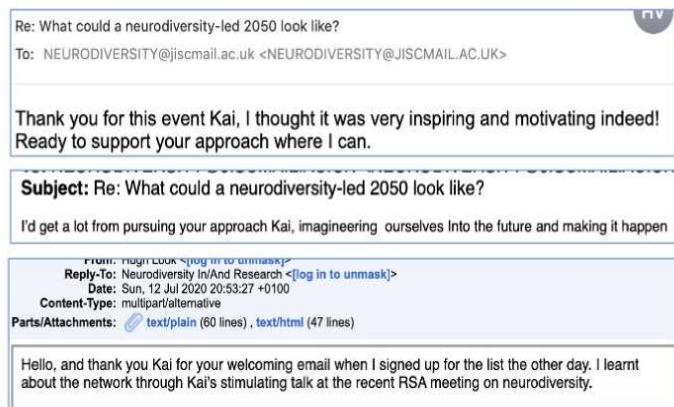
about the network through Kai's stimulating talk at the recent RSA meeting on neurodiversity.

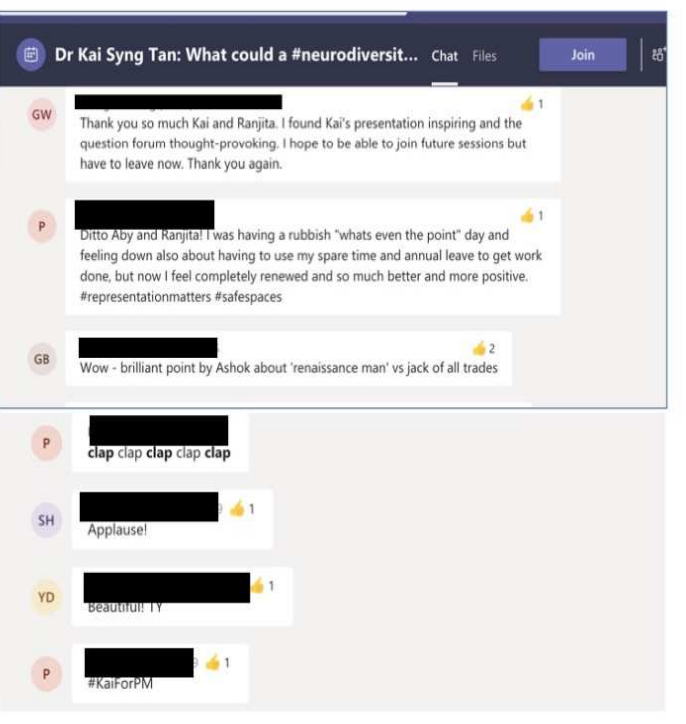

International Journal of Management and Applied Research, 2020, Vol. 7, No. 3 


\section{The Performance-Lecture}

Drawing on pedagogy, performance art, theatre, protest art and activism, and co-opting the conventions and materialities of the classroom (such as blackboard, chalk, slide projector, podium, and even students, as well as performers assuming the role of student), various forms of the performative pedagogy, 'performance-lecture' or 'lecture-performance', have been around as an artistic device since at least the 1970's (Firunts, 2016). Exposing and critiquing the mechanisms and politics of the traditional lecture format and, more generally, how knowledge is constructed and communicated, and aligned with the art historical tradition of performance art, the performance-lecture, which is the term that I will use here, can be understood as not 'just' a lecture, but a mode of meta-lecture that is highly self-reflexive. Blurring the lines between disciplines, and between art and discourse about art, the most interesting instances are those on institutional critique, and are created by artists also believe in power of learning and teaching for socio-political change (Milder, 2011).

I have used, and abused, the performance-lecture format as an artist, teacher and researcher since 2004. Through crafting a series of image-centred slides to spoken words across time, I aim to persuade, provoke, confuse, amuse and bemuse. Rather than to explain, represent or illustrate, I often use images in metaphorical or paradoxical ways.

This draws on my artistic and curatorial practice in filmmaking specialising in the 'cine-essay', which can be described broadly as a poetic, creative-non-fictional format blending autobiography, socio-political critique and storytelling, with roots in 1920s Marxist filmmaking and montage (Tan, 2008). I am also informed by the phenomena of the 'laptop performance', where a computer and what it shows on a screen are the key tools and props for an otherwise, deliberately deadpan and detached bodily presence by the performer common in the electronic band Kraftwerk in the 1970's, through to 'laptop orchestras' of Tokyo in the 2000s, which I was also a part of (Tan, 2004). It was a live performance-lecture by Walid Raad, a Lebanese-American artist and academic that I experienced in 2003 that convinced me to begin using PowerPoint as an artistic medium. Raad's artful appropriation of the aesthetics of the lecture (lamp, table, laptop in a darkened space with the illuminated Apple logo, and even folders in his laptop), in a trademark aloofness and authority as he analysed the Lebanese civil war, was chillingly disturbing as it was laugh-out-loud funny, raising questions about semiotics, fiction, memory and power (including his own as an artist) (Tan in Cobby, 2014). He was at a sage on stage - and a jester, albeit one that is poker-faced, suited and bespectacled.

In my performance-lectures, meaning (within and between each slide) and audience participation, interpretation and experience are key. Each slide and the accompanying spoken words are scripted and timed, and land with punchlines or punches. My slides are image-centred, and typically contain words too. The images may include images from the news or my own or others' artwork. The text may include scholarly citations and captions for images, or questions and provocations, but are treated as visual elements within each slide, akin to a picture, map or poster. In other words, the slideshows are ordered visually, which is how I order my world as a dyslexic, visual thinker, and can thus also be more accessible for students who are think visually,

International Journal of Management and Applied Research, 2020, Vol. 7, No. 3 
which is common in neurodivergent people (Grant, 2010). Contrasts - not continuity govern these PowerPoints, as if to undermine its own authority. Nothing is at facevalue. Audiences - including learners - must stay alert and active, thus engaging in higher order learning and creative thinking, recalling and applying theories and concepts. The slideshows are user-unfriendly, as they self-reflexively segue, employ jarring colours and contradict themselves. Jokes, in-jokes and meta-jokes abound: within and between the slides are tricks including wordplay, puns (as also hinted in the title of this paper), visual puns, image-within-image, juxtaposition, jump cuts, subtexts, simulacra, layering and palimpsests.

In the last 16 years, I have created around 100 different performance-lectures. PowerPoint's blandness allows me to use it to respond quickly to issues and concepts, including around urban alienation (Tan, 2015) and UK's hostile immigration policy (Tan, 2018). In recent years, I would upload the slideshows, scripts, recordings onto Issuu, Academia and Vimeo, to widen access. With Covid-19, the rhetoric of 'we're all in this together' set against the live horror spectacle of its impacts on marginalised groups, fortified my campaign for equality (or rather, equity), (neuro)diversity and inclusion. Through 7 new commissioned performance-lectures between March-July, I launched critiques against disciplinary silos (2020a) and performative-allyship, in response to the 'Blackout Tuesday' farce (Figure 5). To suit online audiences, I now keep my presentations short (5-10 minutes instead of 20-90 minutes), and have reduced the number of slides (from often 200 within a given presentation, to no more than 15).

However, I have not compromised the messages. Or the cheesy jokes.

Figure 5: Two slides from This is Not an Ally (Tan, 2020c)

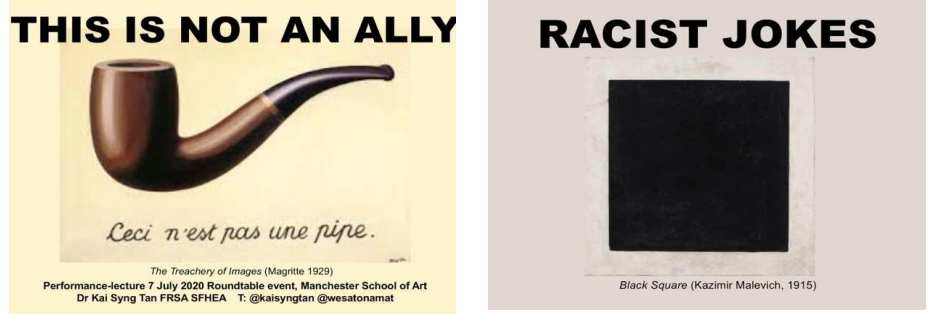

YOU'RE STILLL NOT AN ALLY AL

Source of images from left to right: Magritte (1929); Malevich (1913)

\section{A Powerful Moment - or Another Missed Opportunity?}

This paper outlines an example of a visual-led approach to the learning and teaching of complex issues could look like for a short online synchronous session, using PowerPoint. My example of the performance-lecture incorporates tactics from performance art, activism and film, to raise questions around power and inequality in an engaging manner, and seeks to empower learners as active participants, including those who may be neurodivergent, or are visual thinkers (Figure 6). Inclusive pedagogy and the role of irony in learning and teaching are yet other key elements to add to this discussion. I have not had the time in this paper, but welcome others to do so.

International Journal of Management and Applied Research, 2020, Vol. 7, No. 3 
My example can be added to MML toolkits and yet other examples that HE colleagues can use or are using to facilitate higher order learning and creative thinking. Admirable examples of these include Visual Minutes (www.morethanminutes.co.uk/visual-

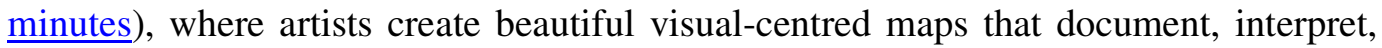
sharpen and make academic concepts accessible, from academic conferences, and a new animation All in the Same Boat (Build Back Better, 2020) which explains how Covid-19 impacts social, environmental and health injustices.

Covid-19 and BLM present a powerful moment for HE to address issues and embrace steps to radically diversify learning and teaching, including embracing the visual - but will it grab it? The pandemic has accelerated digital migration (Kosciejew, 2020) while sharpening the digital divide (Buchholz et al., 2020), make HE to re-evaluate its norms (e.g. Buchholz et al., 2020; Crawford et al., 2020) or encourage creative learning and teaching initiatives: for example, as documented in mailing list JISCMail 2020, itself an example of technology-enabled solidarity. HE can, and must, do better, amid a profoundly unequal socio-political reality, which $\mathrm{HE}$ is situated within, and is responsible for, and which issues such as racism abound that it must address and not avoid. Multimedia learning and visual tools present creative tools to help this culture change. As a simple yet versatile and responsive format, a PowerPoint performancelecture is well-suited for an online interface, by learners and teachers with reduced resources, and to raise questions around difficult topics. I welcome feedback and challenges, and call for the creation of yet more playful, innovative visual-led approaches in HE to encourage reflecting, opening up and sharing, and to provide the learner with insights into complex situations and the understanding of self and others.

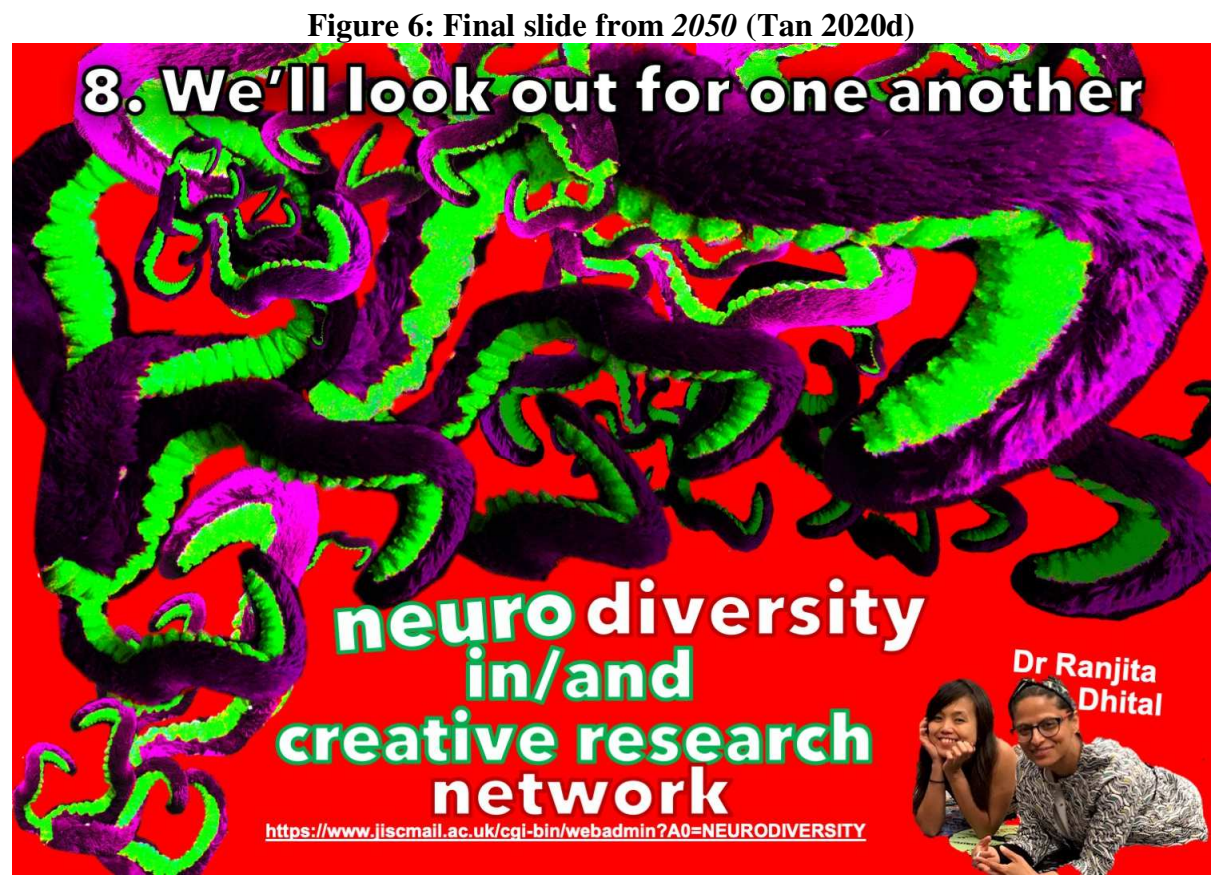

The background artwork was created by the author from photographs of a soft toy taken by the author, while the cropped photo was taken by the crew of \#MagicCarpet (Tan 2017).

International Journal of Management and Applied Research, 2020, Vol. 7, No. 3 


\section{References}

1. Adomako Ampofo, A. (2016), "Re-viewing Studies on Africa, \#Black Lives Matter, and Envisioning the Future of African Studies", African Studies Review, Vol. 59, No. 2, pp. 7-29. https://doi.org/10.1017/asr.2016.34

2. Bartsch, R. A., and Cobern, K. M. (2003), "Effectiveness of PowerPoint Presentations in Lectures", Computers \& Education, Vol. 41, No. 1, pp. 77-86. https://doi.org/10.1016/S0360-1315(03)00027-7

3. BBC News (2020), "Drama School Ex-Head Apologises for Racist Remarks", BBC News, 12 June 2020, [Online] Available from: https://www.bbc.com/news/entertainment-arts-53027976 [Accessed on 27 July 2020].

4. Bhopal, K. and Henderson, H. (2019), Advancing equality in higher education: An exploratory study of the Athena SWAN and Race equality charters, Birmingham: British Academy/Leverhulme Trust.

5. Bhopal, K. and Pitkin, C. (2020), "Same old story, just a different policy: race and policy making in higher education in the UK", Race Ethnicity and Education, Vol. 23, No. 4, pp. 530-547. https://doi.org/10.1080/13613324.2020.1718082

6. Bruns, A, Highfield, T., and Burgess, J. (2013), "The Arab Spring and Social Media Audiences: English and Arabic Twitter Users and Their Networks", American Behavioral Scientist, Vol. 57, No. 7, pp. 871-898. https://doi.org/10.1177/0002764213479374

7. Buchholz, B.A.; DeHart, J. and Moorman, G. (2020), "Digital Citizenship During a Global Pandemic: Moving Beyond Digital Literacy", Journal of Adolescent \& Adult Literacy, Vol. 64, No. 1, pp. 11- 17. https://doi.org/10.1002/jaal.1076

8. Build Back Better (2020), All in the Same Boat [Online] Available from: https://vimeo.com/444081615 [Accessed on 8 July 2020].

9. Catani, M. and Mazzarello P. (2019), "Grey Matter Leonardo Da Vinci: A Genius Driven to Distraction”, Brain, Vol. 142, No. 6, pp. 1842-46. https://doi.org/10.1093/brain/awz131

10. Cobby, H. (2014), "How to Stop Worrying and Love (Running) Kai Syng Tan Interview", UCL Culture Blog. [Online] Available from: https://blogs.ucl.ac.uk/museums/2014/02/06/how-to-stop-worrying-and-loverunning/ [Accessed on 8 July 2020].

11. Crawford, J.; Butler-Henderson, K.; Rudolph, J.; Malkawi, B.; Glowatz, M.; Burton, R.; Magni, P. and Lam, S. (2020), "COVID-19: 20 countries' higher education intra-period digital pedagogy responses", Journal of Applied Learning \& Teaching, Vol. 3, No. 1, pp. 1-20. https://doi.org/10.37074/jalt.2020.3.1.7

12. Empire Medals (2020), OBE Civilian [Online] Available from: https://www.empiremedals.com/products/obe-civilian [Accessed on 22 July 2020].

13. Encyclopaedia Britannica (2020), Microsoft PowerPoint | Software, [Online] Available from: https://www.britannica.com/technology/Microsoft-PowerPoint [Accessed on 8 July 2020].

International Journal of Management and Applied Research, 2020, Vol. 7, No. 3 
14. Firunts, M. (2016), "Staging Professionalization", Performance Research, Vol. 21, No. 6, pp. 19-25. https://doi.org/10.1080/13528165.2016.1240924

15. Grant, D. (2010), That's the Way I Think: Dyslexia, Dyspraxia, ADHD and Dyscalculia Explained. $2^{\text {nd }}$ ed. London: Routledge. https://doi.org/10.4324/9780203857960

16. Hanna, W. (2007), “The New Bloom's Taxonomy: Implications for Music Education", Arts Education Policy Review, Vol. 108, No. 4, pp. 7-16. https://doi.org/10.3200/AEPR.108.4.7-16

17. Haynes, C. and Bazner, K. J. (2019), "A message for faculty from the present-day movement for black lives", International Journal of Qualitative Studies in Education, Vol. 32, No. 9, pp. 1146-1161. https://doi.org/10.1080/09518398.2019.1645909

18. Hellberg, A. (Photographer) (2018), Outside the Swedish Parliament Building, Greta Thunberg Started a School Strike for the Climate [Photograph] Available from: https://commons.wikimedia.org/wiki/File:Greta_Thunberg_4.jpg [Accessed on 20 August 2020].

19. Ibrahim, Y. (2018), "The Unsacred and the Spectacularized: Alan Kurdi and the Migrant Body", Social Media + Society, https://doi.org/10.1177/2056305118803884

20. JISCMail (2020), What is JiscMail?, [Online] Available from: https://www.jiscmail.ac.uk/about/whatisjiscmail.html [Accessed on 20 July 2020].

21. Kosciejew, M. (2020), "The coronavirus pandemic, libraries and information: a thematic analysis of initial international responses to COVID-19”, Global Knowledge, Memory and Communication, https://doi.org/10.1108/GKMC-042020-0041

22. Lee, P. S. N.; So, C.Y.K. and Leung, L. (2015), "Social Media and Umbrella Movement: Insurgent Public Sphere in Formation", Chinese Journal of Communication, Vol. 8, No. 4, pp. 356-75. https://doi.org/10.1080/17544750.2015.1088874

23. Magritte, R. (1929), The Trechery of Images. [Painting] Available from: https://en.wikipedia.org/w/index.php?title=File:MagrittePipe.jpg\&oldid=59804149 $\underline{3}$ [Accessed on 20 July 2020].

24. Malevich, K. (1913), Black Square. [Painting] Available from: https://commons.wikimedia.org/wiki/File:Kazimir_Malevich, 1915, Black Supre matic Square, oil on linen canvas, 79.5 × $79.5 \mathrm{~cm}$, Tretyakov Gallery, Mosc ow.jpg [Accessed on 20 July 2020].

25. Mangione, S., and Maestro, R.D. (2019), "Was Leonardo Da Vinci Dyslexic?", The American Journal of Medicine, Vol. 132, No. 7, pp. 892-93. https://doi.org/10.1016/j.amjmed.2019.02.019

26. Marton, F., and Säljö, R. (1976), "On Qualitative Differences in Learning: IOutcome and Process", British Journal of Educational Psychology, Vol. 46, No. 1, pp. 4-11. https://doi.org/10.1111/j.2044-8279.1976.tb02980.x

International Journal of Management and Applied Research, 2020, Vol. 7, No. 3 
27. Mayer, R.E. (2014), The Cambridge handbook of multimedia learning, $2^{\text {nd }}$ ed., New York: Cambridge University Press.

28. Milder, P. (2011), 'Teaching as Art: The Contemporary Lecture-Performance'. PAJ: A Journal of Performance and Art, Vol. 33, No. 1, pp. 13-27. https://doi.org/10.1162/PAJJ_a_00019

29. Nerantzi, C. (2018), "LEGO® SERIOUS PLAY® As An Affective Experience In Doctoral Researchers' Support: Tensions And New Freedoms", International Journal of Management and Applied Research, Vol. 5, No. 4, pp. 290-303. https://doi.org/10.18646/2056.54.18-022

30. Roberts, D. (2017) “The Message Is the Medium: Evaluating the Use of Visual Images to Provoke Engagement and Active Learning in Politics and International Relations Lectures", Politics, Vol. 38, No. 2, pp. 232-249. https://doi.org/10.1177/0263395717717229

31. Roberts, D. (2018), "The engagement agenda, multimedia learning and the use of images in higher education lecturing: or, how to end death by PowerPoint", Journal of Further and Higher Education, Vol. 42, No. 7, pp. 969-985. https://doi.org/10.1080/0309877X.2017.1332356

32. Røsstad, A. 2002. '[Leonardo da Vinci--a dyslectic genius?]'. Tidsskrift for Den Norske Laegeforening: Tidsskrift for Praktisk Medicin, Ny Raekke 122 (30): 2887-90.

33. Sian, K. P. (2019), Navigating Institutional Racism in British Universities. Cham: Palgrave Macmillan. https://doi.org/10.1007/978-3-030-14284-1

34. Stark, L. and Crawford, K. (2015), "The Conservatism of Emoji: Work, Affect, and Communication", Social Media + Society, https://doi.org/10.1177/2056305115604853

35. Tan, K. S. (2004), "One of the Greatest Shows on Earth: An Invitation to a Discourse about Our Pasts, Hard-to Define Present/Presence and Hereafte via a Not-yet-Defined Presentation Mode", In: Yap, J. (Ed), Twilight Tomorrow, Singapore: Singapore Art Museum.

36. Tan, K. S. (2008), “The Search for Meaning Lies in Language Lies in the Search for Meaning Lies in Language Lies... Some Sketches on the so-Called South East Asian Essay Film", In: Pery, E. (Ed), Cinema South International Film Festival Catalogue, Sapir Film School.

37. Tan, K. S. (2015), "Running (In) Your City", AAG2015 Chicago Premiere. [Online] Available from: https://prezi.com/8ozt2o5k013q/2015-gig-running-inyour-city-aag2015-chicago-premiere/ [Accessed on 22 July 2020].

38. Tan, K. S. (2017), \#MagicCarpet: An Art-Psychiatry Commission. [Online] Available from: www.wesatonamat.weebly.com [Accessed on 22 July 2020].

39. Tan, K. S. (2018), Exceptional Talent, the State of Fun \& Islands of after Death: A Story in 100 Slides. [Online] Available from: https://issuu.com/kaisyngtan/docs/2018aug_exceptional_kaisyngtan_lowr [Accessed on 22 July 2020].

International Journal of Management and Applied Research, 2020, Vol. 7, No. 3 
40. Tan, K. S. (2020a), “TRANSCRIPT: 10 Reasons to Collaborate with Neurodiverse \& Creative Allies", Artists Information Blog [Online] Available from:

https://www.a-n.co.uk/blogs/transcript-10-reasons-to-collaborate-withneurodiverse-creative-allies/ [Accessed on 22 July 2020].

41. Tan, K. S. (2020b), "Novel Viruses Require Artful Solutions - RSA", Royal Society of the Arts Blog, [Online] Available from: https://www.thersa.org/discover/publications-and-articles/rsacomment/2020/05/novel-viruses-require-artful-solutions [Accessed on 22 July 2020].

42. Tan, K. S. (2020c), This Is Not An Ally. [Online] Available from: https://issuu.com/kaisyngtan/docs/07-07_thisisnotanally_drkaisyngtan_lowres

43. Tan, K. S. (2020d), What Could a Neurodiversity-Led 2050 Look Like? Performance-lecture. [Online] Available from: https://www.academia.edu/43602890/2020 What could a neurodiversityled 2050 look like Royal Society of Arts [Accessed on 22 July 2020].

44. University of Reading (2020), Disabilities, COVID-19, Higher Education and Future Neurodiversity, [Online] Available from: http://www.reading.ac.uk/internal/staffportal/news/articles/spsn-845459.aspx [Accessed on 22 July 2020].

International Journal of Management and Applied Research, 2020, Vol. 7, No. 3 